\title{
Pagney Pierre, L'incertitude climatique et la guerre
}

Paris, L'Harmattan, 2016, 229 p.

Philippe Boulanger

\section{OpenEdition}

\section{Journals}

Édition électronique

URL : https://journals.openedition.org/geohist/1418

DOI : $10.4000 /$ geohist. 1418

ISSN : 2264-2617

Éditeur

Association française de la Revue de géographie historique

Référence électronique

Philippe Boulanger, «Pagney Pierre, L'incertitude climatique et la guerre », Revue de géographie historique [En ligne], Comptes-rendus, mis en ligne le 20 novembre 2016, consulté le 12 juin 2021. URL : http:// journals.openedition.org/geohist/1418; DOI : https://doi.org/10.4000/geohist.1418

Ce document a été généré automatiquement le 12 juin 2021.

\section{(c) (i) () $\Theta$}

Ce(tte) œuvre est mise à disposition selon les termes de la Licence Creative Commons Attribution Pas d'Utilisation Commerciale - Pas de Modification 4.0 International. 


\section{Pagney Pierre, L'incertitude climatique et la guerre}

Paris, L'Harmattan, 2016, 229 p.

Philippe Boulanger

\section{RÉFÉRENCE}

Pagney Pierre, L'incertitude climatique et la guerre, Paris, L'Harmattan, 2016, 229 p.

1 Pierre Pagney, professeur émérite de l'Université Paris-Sorbonne et climatologue internationalement reconnu, nous livre des réflexions originales et peu communes dans la géographie académique. Dans Le climat, la bataille et la guerre (2008), il nous avait déjà exposé l'importance de la connaissance des phénomènes climatologiques pour le stratège militaire dans les guerres passées. En s'appuyant sur des exemples issus de cet ouvrage, il développe une nouvelle démonstration tout autant essentielle pour les Etats-majors: l'incertitude climatique. Quel impact peut provoquer l'incertitude climatique sur la décision militaire ? Pour répondre à cette question, Pierre Pagney met en évidence deux aspects tout au long de l'ouvrage : le climat et sa variabilité dans le temps pour le militaire qui conduit à s'interroger sur son incertitude et sa prévisibilité.

2 L'ouvrage s'articule en trois grandes parties qui exposent les caractéristiques les plus importantes en s'appuyant systématiquement sur des exemples passés. Dans « L'Ordre et le désordre climatiques", l'auteur expose "l'aspect climatique» à l'échelle du globe. $\mathrm{Si}$ «l'ordre climatique» aborde la zonation climatique, l'azonalité climatique et la mosaïque climatique du globe, le « désordre climatique » renvoie au caractère climatique de l'atmosphère, la permanence de la variabilité du temps et du climat, aux catastrophes climatiques. Il montre à quel point le niveau stratégique tend à réduire cette incertitude climatique par les nouvelles technologies depuis plusieurs décennies, afin d'anticiper l'organisation des manœuvres militaires. Mais c'est surtout dans la deuxième partie que l'approche militaire est la plus détaillée. Dans «les décisions militaires et l'incertitude climatique» sont traités, dans un ordre qui peut paraître 
original, les opérations continentales, les situations subies comme l'échec du Chemin des Dames (1917), les situations contrôlées comme le débarquement allié en Normandie en juin 1944, les théâtres d'opérations continentaux dans leur rapport à l'incertitude climatique. Dans les exemples exposés, extraits de faits de la Première ou Seconde Guerre mondiales, l'auteur montre que les conditions météorologiques sont toujours fondamentales et exercent une tension sur la prise de décision compte tenu de la variabilité climatique toujours de règle. Enfin, la troisième partie tente de prendre un certain recul en traitant des perspectives géostratégiques et du réchauffement climatique. En s'intéressant aux «conflits potentiels», et en adoptant une démarche régionale, l'auteur tente d'embrasser tous les facteurs de tensions liés à ce phénomène climatique majeur. Autant dire qu'une grande partie des problèmes géopolitiques mondiaux sont cités sans atteindre toutefois un développement approfondi. L'approche se veut donc large, au risque peut-être de perdre le fil directeur de la démonstration qui reste centrée sur la décision militaire. Il n'en demeure pas moins que nous apprenons beaucoup sur le rapport entre incertitude climatique et décision stratégique. L'ouvrage constitue l'un des rares à traiter de cette problématique et à nous la rendre compréhensible. 